\title{
Comunidade de aprendizagem da docência em estágio curricular obrigatório: aprendizagens evidenciadas pelos licenciandos
}

\section{Teaching learning community in mandatory curricular training: learning evidenced by undergraduates}

\author{
Rafael Soave Guerta ${ }^{1}$ • Cristiane Cordeiro de Camargo ${ }^{2}$
}

\begin{abstract}
Resumo: Estudos recentes na área de formação de professores têm se preocupado em entender quais são os saberes envolvidos na prática docente, bem como os processos de desenvolvimento de tais conhecimentos. O presente trabalho, inserido no paradigma da racionalidade prática, fundamenta-se na concepção de que a construção e acúmulo de conhecimentos pelo professor se dão ao longo de sua vida, por meio de suas experiências pessoais, formativas e profissionais, e compreende a reflexão como processo potencializador da aprendizagem profissional da docência. Participaram desta investigação alunos graduandos do curso de Licenciatura em Ciências Biológicas no período de estágio curricular obrigatório, cujas práticas formativas configuraram uma comunidade de aprendizagem. Foram investigados os diferentes tipos de conhecimentos docentes e em quais ambientes de aprendizagem sua aquisição foi favorecida durante o período de estágio. As potencialidades do estágio inicial como período de intensa aprendizagem docente, bem como algumas dificuldades e sugestões, são discutidas.

Palavras-chave: Formação inicial de professores. Estágio curricular. Prática reflexiva. Ensino de biologia. Ambiente de aprendizagem.

Abstract: Recent studies in the area of teacher education have shown concern in understanding which knowledge is involved in teaching practice as well as the development processes of such knowledge. Inserted in the paradigm of practical rationality, this work is based on the conception that the construction and accumulation of knowledge by the teacher takes place during his/her life by means of personal and professional experiences, and sees reflection as a source of professional learning. Graduate students of the BSc in Biological Sciences participated in this research during their compulsory curricular traineeship, whose formative practices configured a learning community. We assessed the different types of knowledge among teachers, and in which learning environments its acquisition was favored during the internship period. The potentialities of the initial stage as a period of intense teacher learning, as well as some difficulties and suggestions, are discussed.
\end{abstract}

Key words: Initial teacher education. Compulsory traineeship. Reflective practice. Biology teaching. Learning environment.

\footnotetext{
${ }^{1}$ Irish Raptor Study Group (IRSG), Griffith College Cork, Cork City, County Cork, Ireland.

E-mail: <rsguerta@gmail.com>

${ }^{2}$ Instituto Federal de Educação, Ciência e Tecnológia do Sul de Minas Gerais, Inconfidentes, MG, Brasil.
} 


\section{Introdução}

Estudos relacionados aos saberes dos docentes têm aumentado nos últimos anos, inseridos em diferentes abordagens teórico-metodológicas sobre como ocorre o processo de aprender a ensinar (ALVES, 2007; MARCELO, 1998). Dentro deste campo, uma das abordagens é direcionada a investigar: que tipos de conhecimentos são essenciais para ensinar, como eles são aprendidos pelos professores, e quais processos influenciam e determinam quanto do conhecimento adquirido pelo professor em formação inicial será usado na prática (ALMEIDA; BIAJONE, 2007; BORGES, 2001; NUNES, 2001). O conhecimento profissional docente, por ser complexo, dinâmico e multifacetado, dificulta a existência de uma teoria geral sobre a aprendizagem da docência, e, por isso, coexistem diversas abordagens e classificações dos diferentes tipos de conhecimentos do professor (ALVES, 2007; MARCELO-GARCÍA, 1992; NUNES, 2001).

Uma etapa importante no desenvolvimento dos conhecimentos docentes é o período de formação inicial. Freire (2001), por exemplo, referindo-se especificamente ao estágio, afirma que o mesmo pode se configurar como uma etapa de um processo de emancipação profissional e de construção de conhecimentos na ação. No entanto, diversos autores, como Marcelo-García (1993) e Lima e Reali (2002), chamam a atenção para pesquisas que apontam os cursos de formação inicial como tendo uma baixa eficiência para a aquisição de novos conhecimentos pelos futuros professores, e a pouca influência destes em sua prática futura. A despeito de suas limitações, há que se reconhecer esta como uma etapa fundamental do processo formativo do professor. A formação inicial pode ser compreendida de diferentes maneiras dependendo da perspectiva que se tenha sobre a aprendizagem da docência.

Uma destas perspectivas está inserida na lógica da racionalidade técnica. De acordo com Shön (1983 apud MIZUKAMI et al., 2002, p. 13), tal perspectiva considera a atuação profissional como uma aplicação de conhecimentos teóricos que se aprende por acumulação ao longo de um processo formal de formação, em nível Médio ou de uma licenciatura, complementado por cursos de capacitação profissional ao longo da carreira. Observa-se, portanto, que, segundo esta maneira de conceber a atuação docente, a formação inicial, complementada por atividades de formação continuada, é o momento exclusivo da formação docente, aquele no qual o professor estaria aprendendo o repertório de fatos, princípios, regras e procedimentos que, mais tarde, irá aplicar em sua atuação profissional. Este modelo de formação docente toma o professor como um técnico especialista, que aplica em seu trabalho regras derivadas do conhecimento científico. Estas mesmas autoras ressaltam que essa perspectiva é a que prevaleceu até recente período da história da educação, embora hoje se reconheçam as suas limitações. Tais limitações explicam-se pelo fato de, no percurso profissional, o professor se deparar com situações práticas que não se encaixam ou não são resolvidas apenas por essa lógica, o que o obriga a ir além das regras, teorias e procedimentos conhecidos, e necessita criar novas estratégias de ação, novos modos de enfrentar e definir problemas (MIZUKAMI et al., 2002).

Por esse motivo, a aprendizagem da docência pode ser entendida a partir de outra racionalidade, denominada racionalidade prática, na qual o profissional é como um artista reflexivo (perspectiva mais ampla que a de um técnico) e a prática tem papel fundamental na aprendizagem do professor para a construção de seu próprio pensamento, o qual incorpora e transcende o conhecimento emergente da racionalidade técnica. É possível dizer que a racionalidade prática 
não nega a racionalidade técnica, mas, sim, a inclui e supera. Nessa perspectiva, a aprendizagem da docência é um processo complexo que não se inicia e tampouco se encerra na formação inicial, embora tenha, nessa fase, um estágio privilegiado para o desenvolvimento de concepções e orientações práticas com relação ao ensino e à aprendizagem (MIZUKAMI et al., 2002). Além disso, ela se caracteriza, segundo Marcelo-García (1992, p. 54-55), como "um processo que tem de manter alguns princípios éticos, didáticos e pedagógicos comuns, independentemente do nível de formação em causa". Assim sendo, a formação docente deve ser compreendida como um continuum, ou seja, "um processo de desenvolvimento para a vida toda - career-long ou life-long career.” (KNOWLES; COLE, 1995 apud MIZUKAMI et al., 2002, p. 13).

Partindo desta concepção sobre o desenvolvimento da docência, este trabalho pretende contribuir com conhecimentos sobre a prática escolar durante a formação inicial docente, analisando, em especial, o estágio curricular como oportunidade para a aprendizagem da docência. Busca-se compreender os tipos de aprendizagem apontados por licenciandos em estágio curricular, bem como os ambientes nos quais eles ocorrem, partindo da premissa de que não é apenas o ambiente da sala de aula que contribui para a aprendizagem profissional da docência, mas, também, aqueles exteriores à mesma e que são igualmente importantes para a formação docente. Essa perspectiva alinha-se a uma necessidade de conhecer melhor como estão estruturados os estágios nos cursos de formação docente, uma vez que pouco se conhece sobre como se articulam aos cursos de licenciatura nos quais estão inseridos, como são realizados e orientados (UNESCO, 2009). Acreditamos que o entendimento de quais aprendizagens podem ser propiciadas aos professores iniciantes - e em quais ambientes tais aprendizagens podem ser favorecidas nas experiências de estágio curricular obrigatório - possibilite contribuir para um melhor planejamento e estruturação tanto dos estágios quanto das disciplinas pedagógicas e de conteúdo disciplinar específico nas instituições formadoras.

\section{Fundamentação teórica}

Assumimos, neste trabalho, que a perspectiva da racionalidade prática é a que melhor compreende o desenvolvimento da docência, por ser a que mais amplamente considera a natureza do trabalho docente e a sua aprendizagem. Como ressaltado na introdução deste trabalho, reconhecemos as limitações da racionalidade técnica para a formação de professores, embora esta tenha sido e continue sendo, em muitos casos, o modelo de referência para a formação de professores no Brasil. Coerentemente com esta perspectiva, compreendemos que a aprendizagem da docência ultrapassa os limites dos conhecimentos teóricos advindos dos cursos de formação acadêmicos. Acreditamos, pois, que o aprender a ser professor compreende tipos de conhecimentos, teóricos e práticos, que são aprendidos/construídos em diferentes contextos, e que a prática de ensino permite a reconstrução e formação de saberes específicos da docência. Defendemos, ainda, que ambos os saberes devem estar articulados, tanto nos cursos de formação inicial, foco do presente estudo, quanto na formação continuada, a fim de promoverem o desenvolvimento profissional docente.

Mais especificamente, este trabalho insere-se junto aos estudos que integram a linha de investigação denominada pensamento do professor, que, de acordo com Lima e Reali (2002, p. 221), indicam que "o desenvolvimento profissional de professores não é um estado de maestria que 
se adquire por intermédio de ações formativas pontuais, mas que se trata de um estado nunca acabado, em reconstrução contínua”. Este trabalho também se fundamenta na concepção de que a construção e o acúmulo de conhecimentos pelo professor são potencializados pela reflexão, de modo que a prática do professor está diretamente ligada à prática reflexiva. Nesse sentido, tem-se defendido que a prática profissional deve estar pautada no professor como agente reflexivo. Desse modo, "a reflexão oferece a esses professores a oportunidade de se tornarem conscientes de suas crenças e das hipóteses subjacentes a suas práticas, possibilitando, assim, o exame de validade de tais práticas na obtenção das metas estabelecidas” (MIZUKAMI et al., 2002, p. 49).

Aplicando as ideias de Schön (1992 apud MIZUKAMI et al., 2002, p. 20) à formação de professores, é possível argumentar que o espaço de formação inicial dos futuros docentes é um momento que pode se tornar um practicum reflexivo, no qual professores iniciantes, auxiliados por seus professores compreendidos como tutores, iniciam a reflexão na e sobre a prática cotidiana, envolvendo novos conhecimentos, e não apenas os relativos ao conteúdo específico da matéria a ser ensinada. Segundo Zeichner (1983), a aprendizagem que a reflexão sobre a prática pode propiciar apenas tem sentido quando parte da própria experiência do sujeito, e, nesses termos, destaca o caráter investigativo que o practicum deve ter. De acordo com Mizukami et al. (2002), o practicum representa um espaço de formação que permite ao futuro professor: fazer experiências, testar estratégias de ensino, cometer erros, tentar novamente outras estratégias, e, portanto, refletir constantemente sobre as situações e problemas ocorridos em sua atuação diária. No entanto, compreendemos esse processo reflexivo nos termos em que propõe Pimenta (2002), ou seja, não como processo individual que o professor realiza com vistas a aprimorar suas técnicas de ensino, mas, sim, como um processo coletivo por meio do qual o professor possa tomar consciência das implicações sociais, econômicas e políticas do seu trabalho.

Essa perspectiva sobre a aprendizagem da docência nos coloca diante de questões como: “quais são os saberes que fundamentam a docência?”, "onde eles são aprendidos?”, "como se aprende a ser um professor reflexivo?”. Com relação à questão sobre os conhecimentos docentes, Lee Shulman, personalidade influente não só no campo acadêmico como político-educacional norte-americano, realiza, na década de 1980, uma síntese sobre o ensino de modo geral e sobre questões referentes aos saberes docentes (BORGES, 2001). Shulman propõe dois conceitos importantes (MIZUKAMI et al., 2002): base de conhecimento e ciclo de raciocínio pedagógico. A base de conhecimento é entendida como "o conjunto de compreensões, conhecimentos, habilidades e disposições necessário para atuação efetiva em situações específicas de ensino e aprendizagem" (MIZUKAMI et al., 2002, p. 67). Ela é composta pelo: conhecimento do conteúdo pedagógico, o conhecimento específico do conteúdo e o conhecimento pedagógico do conteúdo (MIZUKAMI, 2004a, 2004b). O ciclo de raciocínio pedagógico corresponde a um conjunto de etapas, que envolvem pensamento e ação: compreensão do conteúdo a ser ensinado; transformação deste conteúdo em um conteúdo a ser ensinado; instrução (atividades de ensino e de aprendizagem propriamente ditas); avaliação (da aprendizagem dos alunos); reflexão e nova compreensão. Esta última etapa é o que caracteriza esse processo como cíclico, pois, ao final dele, o professor tem uma nova compreensão, mais ampliada, dos conteúdos a serem ensinados. Assim, para Shulman $(1986,2004)$, o ciclo de raciocínio pedagógico é o processo pelo qual o professor constrói e aciona os conhecimentos de sua base a fim de ensinar aos seus alunos.

Além destes conhecimentos, as experiências anteriores, incluindo as de aluno, configuram teorias implícitas que influenciam as práticas e interferem: nas tomadas de decisões 
instrucionais, na maneira de conduzir a aula, nas escolhas e avaliação de estratégias de ensino. Assim, a prática profissional se pauta em pensamentos, interpretações, escolhas e valores que fazem parte das teorias práticas e que podem ser consideradas como conhecimento docente de caráter pessoal e particular para determinadas situações de ensino (MIZUKAMI et al., 2002). Há, ainda, outros processos igualmente importantes e que promovem a aprendizagem da docência, como a relação do professor com seus pares e demais agentes escolares inseridos no ambiente de trabalho.

Diante disso, e reconhecendo a pluralidade de processos de ensino/aprendizagem envolvidos na formação profissional, afirmamos que é necessário criar programas de desenvolvimento profissional partilhados entre pares com diferentes níveis de experiência profissional (iniciantes e experientes), que permitam, aos professores, tomarem consciência das teorias pessoais que orientam as suas práticas, e reorientá-las, se assim considerarem necessário. Neste sentido, a criação de comunidades de aprendizagens, dentro das escolas, em uma perspectiva de formação continuada, permite que seus participantes, ou seja, todo o corpo docente e pedagógico, se engajem em novas formas de pensar e raciocinar coletivamente, com maior interação entre os pares (MIZUKAMI, 2004b). Entende-se por comunidade de aprendizagem um grupo de professores no qual exista um engajamento com a aprendizagem dos alunos e, também, com o desenvolvimento profissional de todo o grupo por meio de uma atitude constante de estudo e reflexão sobre os conteúdos de ensino (GROSSMAN; WINEBURG; WOOLWORTH, 2000).

Com base no referencial teórico acima explicitado, o presente trabalho analisa aspectos formativos de um grupo, entendido como uma comunidade de aprendizagem ${ }^{3}$, composto por alunos de graduação aprendendo a ser professores, e pelos seus mestres orientadores responsáveis por disciplinas obrigatórias de estágio curricular, em articulação com alunos, educadores e outros agentes de escolas públicas. Nesse grupo, constituído como uma comunidade de professores, consideram-se os múltiplos contextos nos quais os futuros professores atuam e dois princípios relacionados à melhoria da prática profissional e à crença de que os professores estão em constante aprendizagem dentro de sua área de atuação profissional. Tais princípios referem-se à articulação entre teoria e prática e à relevância que devem ter, nos processos for-

\footnotetext{
${ }^{3}$ Para este estudo, o grupo foi considerado como uma comunidade de aprendizagem segundo a definição de Grossman, Wineburg e Woolworth (2000), porque as atividades para a orientação do estágio supervisionado incluíram momentos de estudo e discussão sobre o conteúdo específico e trocas de experiências e reflexão sobre situações vividas em sala de aula pelos colegas. Nos momentos de preparação de aula, os orientadores de estágio procuravam conferir o domínio do conteúdo específico pelos estagiários e, também, procuravam, por meio de questionamentos, estimular o desenvolvimento de uma compreensão ampla do conhecimento específico em questão. Além destes momentos, aqueles em que os estagiários relatavam e debatiam sobre as experiências ocorridas em sala de aula permitiram tanto a discussão sobre o conteúdo específico objeto da situação relatada, como, também, sobre estratégias mais eficientes para a aprendizagem dos alunos. Desta forma, os grupos de estagiários elaboravam as suas aulas sempre a partir do que era discutido e aprendido nestes momentos de discussão e, algumas, vezes, a mesma aula foi reelaborada e obteve melhores resultados de aprendizagem junto aos alunos da Educação Básica. Assim, por considerar que o foco das atividades de orientação de estágio sempre estiveram voltadas para o desenvolvimento da base de conhecimentos dos professores e para a busca de melhores resultados de aprendizagem junto aos alunos da Educação Básica, o grupo formado pelos licenciandos e seus professores orientadores foi considerado como uma comunidade de aprendizagem da docência.
} 
mativos, as teorias pessoais dos professores. Nosso trabalho estrutura-se sobre a hipótese de que o estágio curricular obrigatório no curso de formação inicial contribui de modo relevante para a formação dos professores iniciantes, e que é possível identificar, nele, diferentes tipos de aprendizagens, bem como os diferentes ambientes nos quais elas ocorrem.

\section{Contexto da pesquisa e procedimentos metodológicos}

A pesquisa foi realizada com cinco alunos graduandos de uma turma composta por vinte e um alunos do curso de Ciências Biológicas - Licenciatura Plena, da Universidade Federal de São Carlos (UFSCar), campus de São Carlos, durante o período de dois anos em que estavam realizando o estágio curricular obrigatório em escolas públicas de Ensino Fundamental e Médio. A escolha dos mesmos deu-se pela disponibilidade em participar da pesquisa. Dos cinco participantes, um era do sexo masculino e os outros quatro do sexo feminino; possuíam entre 23 e 25 anos de idade e pertenciam à mesma turma de graduação. Destes alunos, todos pretendiam seguir na carreira docente.

No início da disciplina de estágio, os alunos da turma dividiram-se em grupos de três ou quatro pessoas, que passaram a acompanhar e ministrar aulas em diferentes séries durante todo o ano letivo. Os cinco alunos participantes dessa pesquisa estavam distribuídos em grupos diferentes. Durante todo o estágio, o professor da escola e responsável pela turma permanecia na sala de aula, porém com mínima ou nenhuma intervenção.

As disciplinas obrigatórias relativas ao estágio supervisionado foram distribuídas entre os quatro últimos semestres do curso (terceiro e quarto anos). No primeiro ano de estágio (2008), os grupos de estágios se dividiram e passaram a acompanhar os professores das três séries do Ensino Médio. Cada grupo ministrava duas aulas semanais referentes à disciplina "Biologia". Este primeiro ano de estágio foi composto por duas disciplinas de oito créditos cada uma, denominadas "Estágio Supervisionado em Biologia I" (primeiro semestre) e "Estágio Supervisionado em Biologia II” (segundo semestre). No segundo ano, em 2009, os grupos de estágio, que sofreram algumas mudanças na sua composição, passaram a acompanhar séries do Ensino Fundamental. O estágio era composto pelas disciplinas de oito créditos cada, denominadas "Estágio Supervisionado em Ciências I", no primeiro semestre, e "Estágio Supervisionado em Ciências II", no segundo semestre. Novamente, cada grupo permaneceu na mesma turma/série durante todo o ano letivo e ministrou quatro aulas semanais referentes à disciplina "Ciências".

Paralelamente às disciplinas de estágio, foram oferecidos componentes curriculares dedicados à orientação para o estágio, as disciplinas denominadas "Orientação para a Prática Profissional em Biologia I e II" e “Orientação para a Prática Profissional em Ciências I e II”, as quais ocorreram ao longo de todos os semestres do estágio. Essas disciplinas, de dois créditos cada uma, também ministradas pelos mesmos professores orientadores do estágio, foram compostas, em parte, por reuniões coletivas semanais com todos os grupos de estágio e, em parte, por encontros entre os membros do grupo de estágio apenas e entre estes e os professores orientadores. Nas reuniões coletivas com todos os grupos, havia leituras e discussões de textos sobre ensino-aprendizagem e relatos das atividades realizadas nas escolas entre os diferentes grupos de estágio. Nas reuniões entre os membros do grupo, havia planejamento e discussão das atividades a serem realizadas na escola. Por fim, tais atividades eram explicadas, discutidas 
ou demonstradas pelos membros do grupo para os professores orientadores antes de serem desenvolvidas nas escolas. Em ambos os tipos de encontros entre professores orientadores e alunos, os orientadores utilizavam situações reais e concretas de vivência durante o estágio como exemplos, e as problematizavam à luz de discussões teóricas, a fim de estimular, nos alunos, perguntas e tomadas de decisão.

A abordagem metodológica da pesquisa foi qualitativa. Após a finalização do estágio supervisionado, foi aplicado um primeiro questionário, com questões abertas e de caráter direto, referentes às concepções que os professores em formação apresentavam sobre a aprendizagem da docência e as oportunidades formativas durante o estágio curricular. Após a leitura das respostas a este primeiro questionário, verificou-se a necessidade de aplicar um segundo, com questões menos diretas, que contemplavam os mesmos conteúdos do primeiro, mas com questões que propunham uma análise mais ampla do estágio no contexto do processo formativo destes alunos. Os participantes que responderam voluntariamente os questionários pertenciam a diferentes grupos de estágio. O método de análise consistiu em identificar, em cada resposta dos sujeitos da pesquisa, a palavra e/ou expressão que representasse o seu núcleo de sentido. As respostas foram classificadas em categorias e/ou subcategorias que agrupassem esses núcleos de sentido por suas semelhanças e diferenças. Tais categorias foram, portanto, criadas empiricamente e representam uma compilação de todas as respostas e opiniões fornecidas pelos sujeitos da pesquisa. Algumas opiniões que foram julgadas como relevantes ao trabalho, mesmo que aparecendo nas respostas de apenas um dos participantes, também foram consideradas.

\section{Resultados e discussão}

\section{Os tipos de aprendizagens no estágio}

Os resultados estão sistematizados segundo duas grandes categorias: os tipos de aprendizagens propiciadas pelo estágio e os ambientes nos quais elas aconteceram.

Segundo os sujeitos da pesquisa, a aprendizagem da docência refere-se tanto à aprendizagem de conhecimentos práticos relativos à aula quanto a processos que envolvem o pensar sobre a prática. Os dois trechos abaixo ilustram essas concepções:

A aprendizagem na formação do professor deve ser todos os conhecimentos que ele adquire ao longo de sua formação, tanto pessoal quanto acadêmica [...] os conbecimentos práticos que temos nos estágios, a própria aprendiragem dos nossos alunos, com a qual sempre devemos nos preocupar. [...] Esses conhecimentos são como preparar aulas, seleção de conteúdos, como elaborar e aplicar avaliações, a postura em sala de aula, a dinâmica dentro da sala de aula, o relacionamento com os alunos. [participante 2]

Acho que a aprendizagem com relação à formação de professor acontece quando somos capazes de formar opiniōes sobre a prática docente e a partir dai transpor nossas ideais e opiniões para o estágio. [...] é ter uma opinião e postura sobre tudo o que se refere à prática docente (avaliação, seleção de conteúdos, preparação de aula, capacidade de auto avaliaģão/reflexão sobre a prática, etc. [participante 4] 
É importante também destacar, no primeiro trecho, a concepção de que a aprendizagem da docência não é um processo estanque, mas que ocorre ao longo da vida do professor e envolve aspectos técnicos e de desenvolvimento pessoal.

A análise dos dados permitiu construir três categorias para os tipos de aprendizagens da docência que são necessárias e possíveis de se adquirir durante o período de formação inicial. A primeira categoria para os tipos de aprendizagem diz respeito aos chamados conhecimentos teóricos, e relaciona-se com as concepções sobre ensino e aprendizagem, papéis sociais de professor e teorias em educação. A segunda categoria, aprendizagem prática, considerada a mais importante pelos participantes, é aquela por meio da qual é possível adquirir aprendizagens procedimentais, como realizar avaliações, selecionar conteúdos e agir em sala de aula. Por fim, a categoria da aprendizagem pessoal, que envolve as experiências pessoais dentro e fora da academia e da escola, não diretamente relacionadas à docência. Com este tipo de aprendizagem, os licenciandos fazem referência às influências que a história pessoal de cada um exerce sobre a prática docente. Os trechos abaixo ilustram essas concepções:

Para termos uma boa formação como professores são necessárias aprendizagem teórica e prática, mas acredito que essa última seja ainda mais importante, pois é o que nos possibilita aplicar as teorias lidas nos artigos além de conhecer de verdade a rotina de uma escola e da sala de aula. Para termos uma boa formação como professores são necessárias aprendizagem teórica, ou seja, o referencial de trabalhos na área da educação para entender e conhecer algumas situaçoos da prática docente e da relação entre professor e aluno; e aprendizagem prática em que as teorias são aplicadas on mesmo percebidas como não aplicáveis. [participante 1]

A nossa aprendizagem de vida mesmo, a aprendizagem na universidade tanto academicamente falando como o lado pessoal também, a aprendizagem da "vivência" da experiência de ser professor, da prática. [participante 2]

O que se verifica no universo das respostas dos participantes com relação aos tipos de aprendizagem durante o estágio é, portanto, uma mescla de concepções que se referem tanto às dimensões práticas da docência quanto àquelas ligadas aos aspectos teóricos, à reflexão sobre a prática e, também, ao desenvolvimento pessoal. Embora, como mencionado anteriormente, as respostas deem grande relevância aos conhecimentos práticos, verifica-se que os licenciandos não restringem as aprendizagens no estágio a essa dimensão. Mesmo quando fazem referência a aprender "como fazer" algo relativo à sua prática docente, é possível identificar aspectos que remetem à dimensão reflexiva, e não ao simples aprender uma técnica, como nos trechos abaixo:

As aprendizagens necessárias e possiveis de adquirir na nossa formação são aquelas que se relacionam a como o professor deve lidar com a sala, como deve ser uma boa aula, como tratar os alunos de forma igual, como transformar uma aula sem sentido para determinados alunos em uma aula que realmente trará conbecimentos para eles. [participante 3] 
Estou aprendendo principalmente como ter postura na sala de aula, como fazer perguntas aos alunos para identificar se de fato está ocorrendo a aprendizagem, como lidar com a falta de interesse na aula, como planejar uma boa aula sem que seja exclusivamente expositiva e no formato lousa-professor. [participante 1]

Nesses trechos, os participantes fazem alusão ao planejamento das aulas e ao enfrentamento de dilemas como, por exemplo, o desinteresse dos alunos. Esses processos não remetem a técnicas em si mesmas mas a questionamentos (os alunos estão aprendendo? como saber se estão aprendendo? por que os alunos não se interessaram pela aula?) e escolhas (sobre métodos de ensino, sobre perguntas a fazer aos alunos, sobre papel da escola) que devem ser feitos pelo professor em sua atividade profissional.

Este resultado pode ser relacionado à perspectiva sobre a aprendizagem da docência que se construiu no processo de estágio, a qual se aproxima da racionalidade prática, como será discutido mais adiante, ao se fazer referência aos dados sobre os ambientes de aprendizagem. É importante lembrar que a racionalidade prática não exclui a técnica, mas a inclui e a transcende. Da mesma maneira, os participantes reconhecem que o estágio é uma oportunidade singular para a aprendizagem de uma série de saberes-fazer, mas não deixam de mencionar e reconhecer a relevância do estágio como oportunidade para refletir sobre a aprendizagem dos alunos e sua motivação para aprender, sobre as teorias educacionais e instrucionais, sobre o papel do professor e da escola, e para desenvolver atitudes, valores e formas de se relacionar com os alunos e com os colegas de profissão. Em algumas respostas, os licenciandos fazem referências explícitas aos termos conhecimentos teóricos e conhecimentos práticos, evidenciando a dicotomia presente na história da formação docente brasileira e na própria estrutura curricular do curso de formação docente, e, portanto, aproximando-se mais de uma perspectiva técnica. No entanto, tomando-se as respostas dos participantes como um todo, é possível afirmar que há um movimento neste grupo que os leva a considerar a aprendizagem da docência para além dos aspectos técnicos, e isso pode estar relacionado à forma como o estágio foi conduzido e que será alvo de análise no próximo item, que se refere aos ambientes de aprendizagem.

\section{Os ambientes de aprendizagem no estágio}

Os ambientes de aprendizagem ao longo do estágio curricular obrigatório identificados pelos participantes se agrupam em duas categorias: ambientes exteriores à escola em que se deu o estágio e aqueles vivenciados na própria escola.

As aprendizagens relativas à escola relacionam-se mais explicitamente às interações professor-aluno e remetem a situações descritas como: aprendizagens sobre como agir em situações inesperadas e se portar com os alunos, fazer uma boa lousa, testar os melhores modos de explicações, aplicar uma avaliação, entre outros. As aprendizagens que se relacionam aos ambientes externos à escola fazem referência às orientações para os estágios, tais como: a preparação de aulas, a elaboração dos objetivos e seleção de conteúdos, métodos de ensiná-los e troca de experiências sobre situações vividas por outros grupos. O trecho abaixo sintetiza essa percepção dos participantes. 
Estou aprendendo principalmente como ter postura na sala de aula, como fazer perguntas aos alunos para identificar se de fato está ocorrendo a aprendizagem, como lidar com a falta de interesse na aula, como planejar uma boa aula explorando outros meios além da lousa e da fala. Essas aprendizagens estão sendo realizadas durante as orientações de preparação de aula (orientação por grupo), nos momentos de troca de experiências nas aulas (borários de orientação coletiva), na preparação individual (elaboração dos objetivos da aula e dos conteúdos a serem abordados, preparação da lousa e reflexão das sugestões feitas nas orientações) e na realização da aula. [participante 1]

Obviamente que essa percepção decorre da própria natureza das atividades dos dois ambientes que configuraram o estágio, mas o que os dados revelam, e que merece uma análise mais cuidadosa, é o relevo que os ambientes coletivos e de preparação tiveram sob a óptica dos participantes. Sobre esses momentos, fica evidente, na fala dos participantes, a importância da discussão entre diversos grupos de estágio e a reflexão coletiva sobre as práticas vivenciadas por cada grupo e por cada indivíduo.

Nesse ambiente também podemos falar tudo o que acontece na sala em que atuamos, sendo este o momento de refletirmos sobre nossas práticas. [...] Porque com o grupo é possivel discutir várias coisas, como elaborar exercícios, pensar em atividades diferentes em que os alunos possam visualizar melhor determinados conteúdos [...] [participante 3]

[...] é preciso discutir com a turma e dentro do grupo, passar pelos "perrengues", nos momento da aula, se deparar com momentos difíceis de lidar, passar afliçōes na hora de selecionar conteúdos, ser coerentes no momento de avaliá-los, etc. Todos esses contextos que acontecem todo o tempo no estágio é que promovem a aprendizagem. [participante 4]

Questões provocativas dos professores nos faziam refletir em todos os encontros de orientação. Além disso, quando líamos textos e discutiamos nas aulas e quando ouviamos os relatos dos outros grupos suas experiências. [participante 4]

Esses aspectos destacados pelos participantes remetem à forma como o estágio foi organizado e à metodologia de trabalho adotada pelos professores orientadores. Os trechos abaixo ilustram esses resultados.

Essas fontes de aprendizagem só foram possiveis graças ao formato do estágio [estágio regente]. Seria muito diferente se não tivéssemos assumido a turma e somente assistido aula de outros professores. [participante 4]

[...] acredito que os momentos mais propicios para reflexão eram os de orientação (aqui acredito que seja pelo modo como XXX e XXX [orientadores] conduzem a 
orientação, não nos dando os métodos eprocessos mastigados diretos, e sim nos fazendo perguntas, para que sozinhos cheguemos à melhor forma da aula. [participante 5]

Os participantes referem-se ao fato de terem podido desenvolver um estágio com muitas experiências de regência, pois, afinal, eles se responsabilizaram por turmas da Educação Básica ao longo de todo o ano letivo, e puderam vivenciar, de forma mais próxima à realidade, o trabalho de um professor. Isso difere das experiências de estágio em que os licenciados passam a maior parte do tempo observando, e as regências se restringem a momentos poucos e isolados do ano letivo. Acompanhar toda uma turma de alunos semanalmente ao longo de um período letivo (um ano) foi uma condição importante para que os estagiários vivenciassem todo o ciclo de raciocínio pedagógico tal como proposto por Shulman (1986). Ao final de cada aula, unidade didática ou tema, os licenciandos puderam refletir sobre a sua forma de ensinar, sobre os resultados de aprendizagem de seus alunos e, até mesmo, sobre os conteúdos de ensino. Vários trechos que já foram mencionados neste trabalho indicam aprendizagens que os licenciandos apontam, relativas a formas alternativas de: ensinar um conteúdo, dar sentido à aula, motivar os alunos desinteressados, ser coerente na avaliação, atingir os objetivos de aprendizagem, ter um novo olhar sobre algo que se toma por conhecido, ser capaz de avaliar seu trabalho como docente etc. Todos esses elementos remetem ao ciclo de raciocínio pedagógico, por meio do qual o professor escolhe e reflete sobre conteúdos, métodos de ensino, formas e resultados de avaliação de seus alunos. Vivenciar todo este ciclo não seria possível, ou seria com limitações, se os estagiários desenvolvessem regências de forma episódica.

Além dessa característica do estágio (ter sido totalmente dedicado ao planejamento, aplicação e avaliação de unidades didáticas), outro aspecto importante sobressai nas respostas dos participantes, e se refere à forma de organização e condução do trabalho de orientação. A organização da orientação para o estágio envolveu: momentos em grupos pequenos (a preparação das aulas pelos alunos do grupo e o encontro destes com os orientadores) e no grupo maior, momento em que se discutiam determinados textos ou temas, e, também, se relatavam as experiências nas escolas. Os alunos identificam todos esses momentos como propiciadores de aprendizagem, o que significa que, além de aprenderem com os orientadores, também aprendiam entre si. Acreditamos que essa forma de organização propiciou mais trocas entre os alunos, de modo que aquilo que um grupo aprendia com determinada experiência de estágio pudesse ser compartilhado no grupo maior, e vice-versa. Outro aspecto importante dessa organização é que ela cria melhores condições para articular teoria e prática, pois parte dos encontros coletivos foi dedicada à leitura e discussão de textos e, parte, aos relatos das experiências de estágio. Uma das respostas do participante de número um, abaixo, aponta para um exemplo de relação teoria-prática construída por ele ao longo de sua participação no estágio.

Pra mim o estágio rendeu muitas reflexões sobre a prática docente principalmente quanto ao ideal de ensino e de aluno que tinha anteriormente à experiência em sala de sala, pois percebi que muita coisa é difícil de ser colocada em prática e que nem sempre uma aula preparada com dedicação e com o objetivo de ser motivadora para os alunos tem o efeito esperado. [participante 1] 
O que se pode depreender de sua fala é que, no início do estágio, ele tinha concepções idealizadas sobre o aluno e sobre o ensino, talvez estimuladas por disciplinas pedagógicas que já havia cursado, as quais a experiência do estágio confrontou com os alunos reais e as condições reais de ensino nas escolas. A resposta do participante não indica uma dicotomia entre teoria e prática, mas, sim, a constatação de que a realidade é mais complexa do que podem alcançar os modelos teóricos construídos sobre ela. Atribuímos esse tipo de concepção do aluno, ao menos em parte, às possibilidades que a organização do estágio criou para articular teoria e prática.

Além destes aspectos relativos à organização do estágio, é importante atentar para a forma de trabalho dos orientadores, que é apontada em dois trechos já citados do participante de número cinco, em que ele faz referência ao fato de os orientadores não lhes "darem os métodos mastigados" e, sim, fazendo questões e orientando a procura pelas melhores formas de trabalhar com os alunos da Educação Básica. Com certeza, essa forma de trabalhar, que confere mais autonomia aos estagiários, está na base de um processo de aprendizagem da docência que concebe o professor como o sujeito dos conhecimentos que orientam a sua prática, e não como um executor de práticas prescritas por outros. Essa análise é coerente com as respostas dos participantes aos questionários, nas quais, em nenhum momento, eles se remetem à aprendizagem de conteúdos estanques (como métodos ou materiais de ensino) para descrever suas aprendizagens no estágio. Eles sempre enfatizam o seu processo de aprender a ser professor, e que está em desenvolvimento ao longo do estágio, como ilustra o trecho abaixo, no qual o participante responde à questão cinco do primeiro questionário.

Acho que esta resposta é o conjunto das respostas 2 e 4. As aprendizagens que estou tendo são as que coloquei na questão 4 e para alcançar essas aprendizagens [que ainda estão em construção] acho essencial que os ambientes, situações e contextos descritos na questão 2 estejam acontecendo, ou seja, épreciso discutir com a turma e dentro do grupo, passar pelos "perrengues" nos momento da aula, se deparar com momentos dificicis de lidar, passar afliçōes na hora de selecionar conteúdos, ser coerentes no momento de avaliá-los, etc. Todos esses contextos que acontecem todo o tempo no estágio é que promovem a aprendizagem. [participante 4]

Desta forma, é possível afirmar que os resultados indicam uma importante característica do estágio e que o diferencia das primeiras experiências de um professor quando ingressa como profissional em um ambiente escolar: a possibilidade do trabalho coletivo articulado em torno da aprendizagem dos alunos e do desenvolvimento profissional dos professores. Esta é a característica mais marcante, do ponto de vista formativo, que esse estágio apresentou. De certa forma, algumas das aprendizagens vivenciadas pelos participantes são típicas do período de indução à docência e poderiam ser experimentadas por eles no momento de ingresso na vida profissional. No entanto, o ambiente de orientação que se construiu em torno das atividades de ensino foi aquele que mais propiciou aprendizagens do ponto de vista dos participantes do estudo, o que ressalta a dimensão formativa que esse tipo de ambiente tem e que, raramente, está presente nas escolas. Se, como ressaltamos no início deste trabalho, a perspectiva da racionalidade prática é a mais adequada tendo em vista as demandas do trabalho docente na atualidade, a forma como essa experiência de estágio foi organizada nos parece adequada ao propósito de formar professores segundo essa perspectiva, e, por isso, os resultados deste trabalho podem 
contribuir com um diálogo em torno do enriquecimento das práticas formativas no âmbito dos estágios supervisionados, como exploraremos nas conclusões deste trabalho.

\section{Conclusão}

Os sujeitos da pesquisa citam as fontes de aprendizagens tomando o estágio curricular como um todo composto pelos diversos ambientes que tornaram tais aprendizagens possíveis.

O próprio estágio é a principal fonte de aprendizagem, porque com o decorrer do estágio vamos aprendendo, enriquecendo aula a aula, conhecendo a turma com que estamos lidando e assim a aprendizagem vai acontecendo, dia a dia. [participante 3]

Isso significa que a própria comunidade de aprendizagem formada se configura como um espaço integrador das aprendizagens. A partir desses resultados é possível identificar e sistematizar alguns aspectos relacionados com a formação inicial para professores e que se desenvolveram durante o estágio curricular obrigatório objeto deste trabalho.

Nas respostas dos licenciandos, foi identificada a formação de um grupo engajado e coeso em relação à aprendizagem dos alunos da Educação Básica, e que permitiu, a seus participantes, desenvolverem novas formas de pensar e raciocinar coletivamente, com grande interação. Como esperamos ter demonstrado em alguns dos excertos dos questionários, os licenciandos, frequentemente, se referem às suas inquietações em torno da aprendizagem dos alunos, do sentido que têm para estes as atividades escolares, a necessidade de motivá-los, de saber se estão ou não aprendendo etc. Essas falas remetem a um coletivo que se reunia em torno do objetivo comum de ensinar aos alunos, ou seja, elas têm como elemento central os alunos da Educação Básica, considerados não como sujeitos ideais, mas como sujeitos reais. Em nenhuma das respostas, os licenciandos se referem a condições precárias de exercício da docência ou ao desinteresse dos alunos como obstáculos instransponíveis para o ensino, ou à impossibilidade de articular teoria e prática. Suas respostas consideram estes aspectos do fazer docente tendo em vista a aprendizagem dos alunos, e não usando-os para justificar as dificuldades enfrentadas no trabalho do professor. Por esses motivos, identificamos, nesse grupo, um coletivo coeso em torno do objetivo de ensinar aos alunos. Esse tipo de coletivo se mostrou similar ao que Mizukami et al. (2002) descrevem como comunidades de aprendizagem, embora formado e estruturado durante as disciplinas de estágio supervisionado no período de formação inicial, e não na escola, como referido pela autora. Essa comunidade se caracteriza por ser uma fonte de apoio, de ideias, de trocas de experiências entre pares, com o objetivo de criar melhores condições de aprendizagem aos alunos.

Foi possível identificar, também, que os professores iniciantes concebem, como ambientes propícios à aprendizagem dos conhecimentos específicos da docência, espaços que vão muito além da sala de aula, incluindo as interações com os colegas e orientadores de estágio nos vários momentos formativos que foram por eles apontados. Esse dado é significativo na medida em que dá relevo às interações dos professores como propiciadoras de aprendizagens. Desdobrando este dado para as situações formativas, tanto em nível inicial quanto continuada, ele aponta para a necessidade de que os professores, iniciantes ou experientes, tenham opor- 
tunidades para interagir com seus pares de forma sistemática e intencional, com o objetivo de promover seu desenvolvimento profissional.

Tendo em vista estes resultados, é possível afirmar que o estágio curricular se mostrou como importante oportunidade para o desenvolvimento dos conhecimentos inerentes ao exercício profissional. Este trabalho descreve o estágio curricular obrigatório como momento de intensa investigação e reflexão, por parte dos futuros professores, sobre a prática docente, e caracteriza-se por proporcionar situações de desenvolvimento profissional e, até mesmo, pessoal. Corroborando Lima e Reali (2002), acreditamos, portanto, que os cursos de formação inicial podem ser momentos importantes para se adquirirem conhecimentos, capacidades e competências durante o período de estágio supervisionado. Acreditamos que isso foi possível, sobretudo, devido ao modo como o estágio foi planejado e executado (por meio de regências, com uma mesma turma ao longo de todo um período letivo, com encontros regulares para planejamento e discussão sobre as aulas, com o suporte de textos e discussões teóricas atreladas às experiências vividas nas escolas), assim como pela natureza das atividades planejadas pelos professores orientadores, as quais permitiram o desenvolvimento de competências, habilidades e atitudes profissionais efetivas e promoveram processos de reflexão. Essa maneira de conduzir as orientações pelos professores orientadores e que prioriza a reflexão sobre a própria prática vai ao encontro do que Zeichner (1993) denomina de uma nova versão de practicum. Reconhecemos, pois, que professores aprendem na prática cotidiana escolar, mas não desconsideramos ou eliminamos a importância da aquisição dos conhecimentos teóricos já construídos nas teorias em educação.

Os resultados deste trabalho corroboram a afirmação de Freire (2001) de que o estágio pode ser uma etapa importante em um processo de desenvolvimento profissional e de construção de uma identidade docente pautada na reflexão sobre a prática. Como ressalta essa autora, esse tipo de estágio propiciou uma postura investigativa sobre as ações realizadas pelos docentes.

Por fim, apesar da potencialidade já discutida sobre esta experiência de estágio curricular e a maneira como ela se desenvolveu, verificou-se uma limitação. Os estagiários limitaram-se a se referir ao processo de aprendizagem ocorrendo dentro da sala de aula e nos encontros coletivos, não identificando o ambiente escolar como um todo como espaço de diálogos e para a aprendizagem coletiva. Embora as diretrizes curriculares nacionais para formação docente insistam em que essa deve ser construída mediante articulação entre as instituições formadoras e as escolas que recebem os licenciandos para experiências de estagiário, não existem políticas públicas específicas e tampouco currículos de formação suficientemente adequados para promover tal articulação. Essas escolas não são preparadas ou incentivadas a receber, colaborar e participar ativamente do processo de ensinar a ensinar.

Sugerimos, pois, que os elementos apontados nesta pesquisa podem subsidiar tanto as escolas quanto as instituições formadoras no que respeita à formulação de propostas para os estágios curriculares obrigatórios. Da mesma forma, entendemos que os dados deste trabalho também apontam sugestões para a organização do trabalho docente nas escolas, sobretudo o trabalho que se dá (ou deveria dar-se) fora do ambiente da sala de aula. A organização dos encontros coletivos entre professores e orientadores que foi adotada no estágio poderia ser adaptada às particularidades de cada escola, para os momentos de reuniões pedagógicas entre os docentes. Pela própria experiência dos autores, esses momentos acabam sendo, de modo geral, subutilizados para o desenvolvimento da docência ou, mesmo, burocratizados, pois não 
consideram os saberes docentes e não se comprometem com o desenvolvimento profissional dos mesmos. É importante salientar que estes momentos deveriam ser considerados como parte da carga horária de trabalho do professor.

Desse modo, acreditamos que os contratos de trabalho a que os professores estão subordinados deveriam explicitar que a prática docente não se restringe ao desempenho do professor em sala de aula, mas que outras atividades, sobretudo os momentos de estudo e de encontros e trocas entre pares, também fazem parte do trabalho do professor. Acreditamos que essas medidas fomentariam o desenvolvimento profissional dos professores já atuantes nas instituições de ensino, o que, por sua vez, permitiria que estes desenvolvessem as competências necessárias a sua atuação como coformadores dos professores iniciantes. Em síntese, tais medidas poderiam contribuir para a efetivação, nos currículos de formação docente, da articulação entre teoria e prática e entre instituições formadoras.

\section{Referências}

ALMEIDA, P. C. A.; BIAJONE, J. Saberes docentes e formação inicial de professores: implicações e desafios para as propostas de formação. Educação e Pesquisa, São Paulo, v. 33, n. 2, p. 281-295, 2007. Disponível em: <http://dx.doi.org/10.1590/S151797022007000200007>. Acesso em: 07 maio 2015.

ALVES, W. F. A formação de professores e as teorias do saber docente: contextos, dúvidas e desafios. Educação e Pesquisa, São Paulo, v. 33, n. 2, p. 263-280, 2007. Disponível em: <http://dx.doi.org/10.1590/S1517-97022007000200006>. Acesso em: 07 maio 2015.

BORGES, C. Saberes docentes: diferentes tipologias e classificações de um campo de pesquisa. Educação \& Sociedade, Campinas, v. 22, n. 74, p. 59-76, 2001. Disponível em: $<$ http://www.scielo.br/pdf/es/v22n74/a05v2274.pdf >. Acesso em: 07 maio 2015.

FREIRE, A. M. Concepções orientadoras do processo de aprendizagem do ensino nos estágios pedagógicos. In: COLÓQUIO MODELOS E PRÁTICAS DE FORMAÇÃO INICIAL DE PROFESSORES, 2001, Lisboa. Lisboa: Universidade de Lisboa, 2001. Disponível em: <http://www.educ.fc.ul.pt/recentes/mpfip/pdfs/afreire.pdf $>$. Acesso em: 30 nov. 2013. (Trabalho não publicado).

GROSSMAN, P.; WINEBURG, S.; WOOLWORTH, S. What makes teacher community different from a gathering of teachers? Seattle: Center for the Study of Teaching and Policy and Center on English Learning \& Achievement, 2000.

LIMA, S. M.; REALI, A. M. M. R. O papel da formação básica na aprendizagem profissional da docência (aprende-se a ensinar no curso de formação básica?). In: MIZUKAMI, M. G. N.; REALI, A. M. M. R. (Org.). Formação de professores, práticas pedagógicas e escola. São Carlos: EdUFSCar, 2002. p. 217-235. 
Guerta, R. S.; Camargo, C. C.

MARCELO, C. Pesquisa sobre a formação de professores: o conhecimento sobre aprender a ensinar. Revista Brasileira de Educação, Rio de Janeiro, n. 9, p. 51-75, 1998. Disponível em: <http://anped.org.br/rbe/rbedigital/RBDE09/RBDE09_06_CARLOS_MARCELO. pdf $>$. Acesso em: 07 maio 2015.

MARCELO-GARCÍA, C. Como conocen los profesores la materia que ensenãn: algunas contribuiciones de la investigacion sobre conocimiento didactico del contenido. In:

MONTERO MESA, L.; VEZ JEREMÍAS, J. M. (Ed.). Las didácticas específicas en la formación del profesorado: conferencia internacional celebrada en la Universidad de Santiago de Compostela, julio de 1992. Santiago de Compostela: Tórculo, 1993. Disponível em: <http://ocw.pucv.cl/cursos-1/epe1137/materiales-de-clases-1/unidad-2/ documentos/carlos-marcelo-como-conocen-los-profesores_la_materia_que_ensenan $>$. Acesso em: 07 maio 2015.

A formação de professores: centro de atenção e pédra-de-toque. In: NÓVOA, A.

(Org.). Os professores e sua formação. Lisboa: Dom Quixote, 1992. p. 51-76.

MIZUKAMI, M. G. N. Aprendizagem da docência: algumas contribuições de L. S. Shulman. Revista do Centro de Educação, Santa Maria, v. 29, n. 2, p. 33-49, 2004a. Disponível em: <http://coralx.ufsm.br/revce/revce/2004/02/a3.htm>. Acesso em: 07 maio 2015.

Relação universidade-escola e aprendizagem da docência: algumas lições de parcerias colaborativas. In: BARBOSA, R. L. L. (Org.). Trajetórias e perspectivas da formação de educadores. São Paulo: Ed. UNESP, 2004b. p. 285-314.

MIZUKAMI, M. G. N. et al. Escola e aprendizagem da docência: processos de investigação e formação. São Carlos: EdUFSCar, 2002.

NUNES, C. M. F. Saberes docentes e formação de professores: um breve panorama da pesquisa brasileira. Educação \& Sociedade, Campinas, v. 22, n. 74, p. 2001.

PIMENTA, S. G. Professor reflexivo: construindo uma crítica. In: PIMENTA, S. G.; GHEDIN, E. (Org.). Professor reflexivo no Brasil: gênese e crítica de um conceito. São Paulo: Cortez, 2002. p. 20-62.

SHULMAN, L. S. Teaching as community property: essays on higher education. Hutchings, P. (Ed.). San Francisco: Jossey-Bass, 2004.

. Those who understand: knowledge growth in teaching. Educational Researcher, Washington, v. 15, n. 2, p. 4-14, 1986.

UNESCO. Professores do Brasil: impasses e desafios. Brasília: UNESCO, 2009.

ZEICHNER, K. A formação reflexiva de professores: idéias e práticas. Lisboa: EDUCA, 1993. Disponível em: <http://repositorio.ul.pt/handle/10451/3704>. Acesso em: 07 maio 2015. 
Apêndice A. Questões aplicadas aos sujeitos da pesquisa

\section{Questionário I}

1. Para você, o que significam ambientes de aprendizagem ou contextos de aprendizagem ou situações de aprendizagem?

2. Quais ambientes de aprendizagem ou contextos de aprendizagem ou situações de aprendizagem você identifica durante o estágio curricular obrigatório? Obs: Consideramos como estágio curricular todos os elementos relacionados ao estágio, não só a nossa participação em sala de aula.

3. Para você, o que é aprendizagem na formação de professor?

4. Quais tipos de aprendizagem são necessários e possíveis de se adquirir na formação inicial (licenciatura) de professores?

5. Descreva quais aprendizagens você está tendo nos processos de estágio. Procure discriminar quais ambientes de aprendizagens ou contextos, ou situações, favorecem o desenvolvimento dessas determinadas aprendizagens.

\section{Questionário II}

1. Onde, ou seja, em quais situações, momentos ou ambientes de aprendizagem, você aprende os conteúdos específicos de Biologia (os fatos, conceitos, processos, procedimentos etc.)?

2. Você consegue lembrar (e descrever aqui) algum caso ou situação pela qual você ou o grupo passou e que, depois de refletir e pensar sobre ela, o grupo ou você mudou o comportamento ou a maneira de dar aquela aula? Se afirmativo, você acha que isso proporcionou uma melhora no processo de ensino-aprendizagem dos alunos?

3. Você acha que seus conhecimentos prévios (anteriores) de quando foi aluno e as suas experiências de aluno são importantes para a formação profissional? Caso a resposta seja afirmativa, explique em que esses conhecimentos e experiências são importantes; caso seja negativa, explique por que eles não influenciam em sua formação profissional.

4. Quais são as fontes das aprendizagens adquiridas no período de estágio obrigatório que você pode identificar, ou seja, de onde provém a aquisição dos diferentes tipos de aprendizagens? Não é necessário descrever novamente as aprendizagens, mas apenas suas fontes.

5. Você acha que as disciplinas de estágio (estágio curricular e as orientações de estágio) proporcionaram momentos de reflexão sobre a prática docente? Se sim, qual(ais) momento(s) ou ambiente(s), ou situação (ões), você identifica como principal(is) proporcionador(es) dessa reflexão? 
